\title{
DESEMPENHO DE BEZERROS LEITEIROS LACTENTES ALIMENTADOS COM FENO
}

\author{
PERFORMANCE OF DAIRY CALVES SUCKLING FED HAY
}

\author{
Oliveira, D.P. de ${ }^{1 *}$; Oliveira, M.V.M. ${ }^{1 A}$; Vargas Júnior, F.M. ${ }^{2}$; Luz, D.F. ${ }^{1 B}$; Simões, A.R.P. ${ }^{1 C}$; \\ Oliveira, C.A.L. ${ }^{3 A}$; Braga Netto, A.L. ${ }^{1 D}$ e Silva, S.C.C. ${ }^{3 B}$
}

\begin{abstract}
${ }^{1}$ Universidade Estadual de Mato Grosso do Sul. Unidade Universitária de Aquidauana. Mato Grosso do Sul. Brasil. ‘dane_portela@yahoo.com.br; Amarcusvmo@uems.br; Bdirceluz@yahoo.com.br; Candrerpsimoes@hotmail.com; Dantenorbraga@zootecnista.com.br

2Universidade Federal da Grande Dourados. Dourados/MS. Brasil. fernandojunior@ufgd.edu.br

3Universidade Estadual de Maringá. Maringá/PR.Brasil.Acaloliveira@uem.br; ${ }^{B}$ stefania_caroline@hotmail.com
\end{abstract}

PaLAVRAS ChaVE ADICIONAIS

Bovino leiteiro. Desaleitamento precoce. Volumoso.

\section{RESUMO}

Objetivou-se estudar a influência da época de fornecimento de feno no desempenho de bezerros leiteiros da raça Girolando, desaleitados aos noventa dias de vida. Foram utilizados 16 animais lactentes, distribuídos num delineamento inteiramente ao acaso. As dietas testadas foram: T1Ração concentrada; T2- Ração concentrada mais feno fornecido a partir do $1^{\circ}$ dia de vida; T3Ração concentrada mais feno fornecido a partir do $30^{\circ}$ dia de vida e T4- Ração concentrada mais feno fornecido a partir do $60^{\circ}$ dia de vida. O feno de alfafa utilizado (Medicago sativa) foi oferecido sem qualquer tipo de trituração. Todos os animais receberam diariamente 4 litros de leite, mais água e ração concentrada a vontade, sendo a ração disponibilizada a partir do $10^{\circ}$ dia de vida. As variáveis observadas foram os pesos corpóreos inicial (nascimento) e à desmama, o ganho de peso diário, as alturas de cernelha e garupa, o perímetro torácico, os consumos de matéria seca, proteína bruta e fibra em detergente neutro e a conversão alimentar. A dieta contendo somente ração concentrada proporcionou desempenho semelhante às dietas contendo ração mais feno; a dieta contendo ração mais feno a partir do $15^{\circ}$ dia de vida proporcionou a melhor receita/custo.

\section{SUMMARY}

The experiment aimed to evaluate the influence

\section{AdDitionAL KEYWORDS}

Dairy cattle. Early weaning. Roughages.

of time of supply of hay in the performance of dairy calves Girolando breed submitted to early weaning at 90 days of life. Sixteen sucking calves were distributed in a completely randomized design. The diets tested were: T1- Concentrate; T2Concentrate plus hay supplied at $15^{\circ}$ day of life; T3- Concentrate plus hay supplied at $30^{\circ}$ day of life; T4- Concentrate plus hay supplied at $60^{\circ}$ day of life. An alfalfa (Medicago sativa) hay was offered without any grinding. All animals received 4 liters of milk daily, plus water and concentrate ad libitum. Concentrate was available from the $10^{\circ}$ day of life. The observed variables were the initial (birth) and weaning body weights; daily weight gain, heights at withers and rump; thoracic perimeter; intake of the dry matter, crude protein and neutral detergent fiber; and feed:gain ratio were also measured. A diet containing only concentrate provided similar performance to diets containing ration plus hay. However, the diet containing ration plus hay from the $15^{\circ}$ day of life provided the best ratio revenue/cost.

\section{INTRODUÇÃO}

A correta criação de bezerras durante a fase de aleitamento é o primeiro passo para o sucesso da atividade leiteira, já que a maior percentagem de mortes em bovinos leiteiros é verificada no primeiro mês de vida 


\section{OLIVEIRA ETAL.}

(Oliveira et al., 2009a).

Além disso, como o leite é um alimento nobre e o principal produto gerador de renda da propriedade leiteira, é desejável que ele seja substituído por uma dieta de menor custo. Segundo Bermudes e Peixoto (1997), a principal forma para se restringir o uso do leite é através do desaleitamento precoce, com o fornecimento antecipado de dietas sólidas, para se estimular o desenvolvimento do retículo-rúmen.

O desenvolvimento fisiológico do estômago aglandular é uma conseqüência do aumento da concentração de ácidos graxos de cadeia curta, que são absorvidos pelas paredes do rúmen, redundando no crescimento das papilas (Baldwin et al. 2004; Costa et al., 2008). Nesse sentido, as rações concentradas, devido a suas características nutricionais, são rapidamente fermentadas pelos microrganismos ruminais, sendo os seus benefícios na aceleração do processo de maturação do retículo-rúmen notoriamente reconhecidos (Nussio et al., 2003; Nielsen, 2008).

Já o feno, apesar do seu fornecimento a bezerros lactentes ser desejável, devido ao maior desenvolvimento dos músculos envolvidos no processo da ruminação e do maior $\mathrm{pH}$ do líquido ruminal, consequência da maior produção de saliva; não é consensualmente recomendado. Assim, existem autores favoráveis a utilização do feno a bezerros lactentes (Zitnan et al., 2005; Oliveira et al., 2007) e outros desfavoráveis, como Suárez et al. (2007) e Khan et al. (2011), por não verificarem influência deste volumoso no desempenho de bezerros leiteiros desmamados precocemente.

Assim, o presente trabalho visou avaliar a influência da época de fornecimento de feno na performance de bezerros leiteiros lactentes, quando submetidos a uma desmama precoce aos noventa dias de vida.

\section{MATERIALE MÉTODOS}

O experimento foi desenvolvido no Setor de Bovinocultura de Leite na Universidade Estadual de Mato Grosso do Sul, localizada no município de Aquidauana-MS, região do Alto Pantanal Sul-Mato-Grossense (20 $27^{\prime}$ 12,33" S; 5540'35,08" W).

Foram utilizados 16 bezerros lactentes da raça Girolando ( $3 / 4$ Holandês e $1 / 4$ Gir), distribuídos num delineamento inteiramente casualizado com 4 tratamentos e 4 repetições, com duas fêmeas e dois machos.

As dietas avaliadas foram: T1- Ração concentrada; T2- Ração concentrada mais feno fornecido a partir do $15^{\circ}$ dia de vida, T3Ração concentrada mais feno de alfafa (Medicago sativa) sem trituração fornecido a partir do $30^{\circ}$ dia de vida e T4- Ração concentrada mais feno fornecido a partir do $60^{\circ}$ dia de vida.

A ração concentrada era constituída por grão de milho triturado na forma de quirera, farelo de soja, melaço em pó como palatabilizante e sal mineral; sendo formulada de modo a atender as exigências nutricionais prescritas no NRC (2001). Nas tabelas I e II podem ser observadas a composição química dos alimentos utilizados na dieta e o percentual dos ingredientes utilizados na

Tabela I. Composição (\% na matéria seca), dos alimentos utilizados. (Composition (\% dry matter) of feeds used).

\begin{tabular}{lccc}
\hline \multirow{2}{*}{ Alimentos } & \multicolumn{3}{c}{ Teor dos nutrientes } \\
& MS & PB & FDN \\
\hline Feno de alfafa & 85,00 & 15,04 & 46,54 \\
Grão de milho & 87,58 & 8,76 & 20,07 \\
Farelo de soja & 88,66 & 44,87 & 15,11 \\
Melaço em pó $^{\text {Sal mineral }}$ & 93,56 & 05,45 & 00,35 \\
& 100,00 & 0,00 & 0,00 \\
\hline
\end{tabular}

MS= Matéria seca; $\mathrm{PB}=$ Proteína bruta; FDN= Fibra em detergente neutro.

*Contendo em cada kg: $25 \mathrm{~g}$ de sulfato de amônio, $75 \mathrm{~g}$ de cloreto de potássio, $425 \mathrm{~g}$ de fosfato bicálcico, $250 \mathrm{~g}$ de calcário calcítico, 209,85 g de sal comum, $12,5 \mathrm{~g}$ de sulfato de zinco, $2,5 \mathrm{~g}$ de sulfato de cobre e $0,15 \mathrm{~g}$ de sulfato de cobalto. 


\section{DESALEITAMENTO DE BEZERROS LEITEIROS COM USO DE VOLUMOSO}

Tabela II. Ingredientes utilizados na ração concentrada e teores de proteína bruta, fibra em detergente neutro e nutrientes digestiveis totais. (Ingredients used in concentrate and contents of crude protein, neutral detergent fiber and total digestible nutrients).

\begin{tabular}{lc}
\hline Ingredientes & (\% na MS) \\
\hline Grão de milho & 54,00 \\
Farelo de soja & 39,60 \\
Melaço em pó & 5,30 \\
Mistura mineral & 1,10 \\
Total & 100,00 \\
& \\
Proteína bruta & 22,79 \\
Fibra em detergente neutro & 16,84 \\
Nutrientes digestíveis totais* & 82,16 \\
\hline *Estimado, segundo dados de Valadares Filho (2000).
\end{tabular}

ração concentrada, respectivamente.

Os bezerros logo após o nascimento foram separados das mães, realizou-se a assepsia do umbigo e forneceu-se o colostro, de modo assegurar uma adequada ingestão de imunoglobulinas. Posteriormente, foram ofertados diariamente 4 litros de leite, divididos em duas refeições (matinal e vespertina) em porções equitativas, mais água e ração concentrada a vontade, sendo a ração disponibilizada a partir do $10^{\circ}$ dia de vida.

Os animais foram mantidos num bezerreiro coletivo construído em alvenaria, com um pé direito de 4 metros. As paredes eram parcialmente fechadas, de modo a permitir uma perfeita ventilação do ambiente, e a cobertura era com telhas de barro. Foi utilizada maravalha como cama para os animais, sendo adicionado semanalmente cal e sulfato de amônio sob uma nova camada de maravalha, para reduzir a incidência de moscas e o cheiro de amônia, oriundo do nitrogênio urinário.

Em cada bezerro foi colocada uma coleira de couro acoplada a um mosquetão, onde foi fixada uma corda com 2,5 metros. Durante o período experimental cada animal teve a sua disposição baldes de metal, com capacidade para 8 litros, onde foi colocada água, ração concentrada e feno, de acordo com os tratamentos.

Os alimentos sólidos foram pesados e fornecidos diariamente, considerando uma sobra de $10 \%$ do oferecido, na matéria natural. Também foram, diariamente, pesadas as sobras dos alimentos ofertados para cada animal. Tanto do alimento ofertado como das sobras diárias de cada animal foram retiradas porções similares de amostras e estas foram mantidas em freezer a $-20{ }^{\circ} \mathrm{C}$. Posteriormente, em intervalos de 14 dias, as amostras do período de cada animal foram descongeladas, colocadas sobre uma bancada e misturadas até sua homogeneização. Em seguida uma amostra foi utilizada para determinação dos teores de matéria seca (MS), proteína bruta (PB) e fibra em detergente neutro (FDN), seguindose os procedimentos descritos por Silva e Queiroz(2002).

O período experimental foi de 90 dias, correspondendo ao período de aleitamento. $\mathrm{Na}$ ocasião do desmame todos os animais apresentaram consumo estável de ração concentrada superior a $1 \mathrm{~kg} / \mathrm{d}$.

A qualidade da dieta foi determinada indiretamente através do desempenho dos animais, por meio do ganho de peso médio diário; do crescimento corpóreo, mensurado pelo perímetro torácico e pelas alturas de cernelha e garupa; dos consumos de matéria seca, expressos em quilos por dia, percentagem do peso corpóreo e em função do peso metabólico, de proteína bruta e de fibra em detergente neutro; e da conversão alimentar.

A pesagem dos animais foi efetuada em balança mecânica logo após o nascimento e, posteriormente, em intervalos de 14 dias, sempre antes do fornecimento do leite no período da manhã. Logo após a pesagem, também foram realizadas as medições nas alturas de cernelha e garupa utilizando-se um hipômetro, e do perímetro torácico, determinado com fita métrica circundando o 


\section{OLIVEIRA ETAL.}

corpo do animal, sendo esta posicionada atrás dos membros anteriores e cruzada por cima da cernelha.

Todas as variáveis analisadas foram inicialmente submetidas aos testes de CramerVon Mises, para verificar a normalidade dos resíduos e de Brown e Forsythe, para homogeneidade entre as variâncias. Os dados foram submetidos à análise de variância considerando os quatro tratamentos e o peso ao nascimento como covariável. O sexo não influenciou nas avaliações estudadas ( $p>0,01$ para o Teste F). As médias dos parâmetros avaliados considerados significativos foram comparadas através do Teste de Tukey a $5 \%$ de probabilidade de erro. As análises foram realizadas utilizando-se o programa estatístico SAS (2002).

Em relação à análise econômica, a mesma foi efetuada considerando-se como despesas gerais apenas os gastos com a alimentação utilizada em cada tratamento. Não sendo, portanto, considerado o custo das instalações e depreciações, as despesas de fluxos de serviços e os medicamentos. O preço médio dos ingredientes utilizados na alimentação dos animais foi determinado no varejo, em função dos valores existentes em casas agropecuárias (tabela III).

Para se avaliar a viabilidade econômica dos tratamentos testados utilizou-se o indicador relação receita/custo (R/C), o qual representa o quociente entre a receita e o

Tabela III. Preço dos alimentos utilizados. (Prices of food used).

\begin{tabular}{lc}
\hline & $\mathrm{R} \$ / \mathrm{kg}$ \\
\hline Feno de alfafa & 1,90 \\
Grão de milho & 0,53 \\
Farelo de soja & 1,27 \\
Melaço em pó & 1,90 \\
Sal mineral & 2,11 \\
\hline
\end{tabular}

US $\$ 1.00=R \$ 2,0315$ custo gerado pelo uso do tratamento. Neste caso, será viável o tratamento que apresentar o valor do receita superior ao valor do custo, ou seja, R/C maior que 1. Quando a relação $\mathrm{R} / \mathrm{C}$ foi igual a 1 , significa que o valor da receita é igual ao do custo, sinalizando que não há perdas nem ganhos econômicos com o uso do tratamento. Finalmente, se a relação $\mathrm{R} / \mathrm{C}$ for menor que 1 , significa que os custos do tratamento superam a receita, mostrando assim a inviabilidade da tecnologia.

\section{RESULTADOSEDISCUSSÃO}

Segundo Lydorf Jr. (1988), animais que recebem feno precocemente apresentam aumento no consumo total de matéria seca, em função da contribuição do feno no desenvolvimento do retículo-rúmen tanto em termos da flora microbiana, quanto no aumento do volume ruminal, com consequente fortalecimento do tecido muscular das paredes do rúmen. Todavia, neste ensaio, os animais que receberam somente leite e ração concentrada apresentaram um consumo estatisticamente semelhante $(p>0,05)$ aos que receberam leite, ração e feno, independentemente da época de inclusão do feno (tabela IV). Entretanto, observou-se menor conversão alimentar nos animais do grupo controle (T1) em relação aos que receberam ração mais feno aos 30 dias (T3), e uma tendência numérica $(\mathrm{p}<0,10)$ de pior conversão também dos tratamentos T2 e T4, com feno fornecido aos 15 e 60 dias, respectivamente. Este fato pode ser explicado pelo maior teor de fibra das dietas com feno, com consequente diminuição da eficiência de utilização dos nutrientes.

Resultados semelhantes também foram observados por Lizieire et al. (2002) ao realizarem experimento com bezerros lactentes de 0 a 56 dias de vida, mestiços holandês x zebu e submetidos a três dietas (T1-Concentrado, T2- Concentrado mais pasto de capim-estrela (Cynodon nlemfluensis) e T3-Concentrado mais feno de alfafa), sendo os consumos de matéria seca

Archivos de zootecnia vol. 62, núm. 239, p. 360. 


\section{DESALEITAMENTO DE BEZERROS LEITEIROS COM USO DE VOLUMOSO}

Tabela IV. Consumos de matéria seca (CMS) de ração e feno e de matéria seca total, peso metabólico e conversão alimentar em função dos tratamentos. (Intake (dry matter) of concentrate and hay; total dry matter intake; metabolic weight, and feed conversion).

\begin{tabular}{lccccc}
\hline Variáveis $^{1}$ & \multicolumn{4}{c}{ Tratamentos $^{2}$} & CV (\%) \\
& T1 & T2 & T3 & T4 & \\
\hline CMS ração $(\mathrm{kg} / \mathrm{d})$ & $0,73^{\mathrm{a}}$ & $0,84^{\mathrm{a}}$ & $0,94^{\mathrm{a}}$ & $0,73^{\mathrm{a}}$ & 31,96 \\
CMS feno $(\mathrm{kg} / \mathrm{d})$ & $0,00^{\mathrm{b}}$ & $0,22^{\mathrm{a}}$ & $0,27^{\mathrm{a}}$ & $0,18^{\mathrm{a}}$ & 44,77 \\
CMS total & & & & & \\
$\quad$ kg/dia & $0,73^{\mathrm{a}}$ & $1,06^{\mathrm{a}}$ & $1,20^{\mathrm{a}}$ & $0,90^{\mathrm{a}}$ & 27,45 \\
$\quad \%$ PC & $1,20^{\mathrm{a}}$ & $1,56^{\mathrm{a}}$ & $1,67^{\mathrm{a}}$ & $1,46^{\mathrm{a}}$ & 21,75 \\
Peso metabólico & $33,40^{\mathrm{a}}$ & $44,74^{\mathrm{a}}$ & $48,55^{\mathrm{a}}$ & $40,84^{\mathrm{a}}$ & 22,86 \\
Conversão alimentar & $1,28^{\mathrm{b}}$ & $1,50^{\mathrm{ab}}$ & $1,93^{\mathrm{a}}$ & $1,49^{\mathrm{ab}}$ & 18,78 \\
\hline
\end{tabular}

a,bMédias seguidas de letras diferentes, na mesma linha, diferem significativamente entre si pelo teste de Tukey $(p<0,05)$.

$\mathrm{T} 1=$ ração; $\mathrm{T} 2=$ ração mais feno aos 15 dias; $\mathrm{T} 3=$ ração mais feno aos 30 dias; $\mathrm{T} 4=$ ração mais feno aos 60 dias. $C V=$ coeficiente de variação.

total entre as dietas estatisticamente iguais. Martuscello et al. (2004) ao substituírem, a partir da $6^{\mathrm{a}}$ semana de idade, $31 \%$ da matéria seca do concentrado por feno de capim coast cross (Cynodon sp.) na dieta de bezerros lactentes mestiços Holandês $\mathrm{x}$ Zebu e desaleitados precocemente aos 49 dias, também não observaram alterações no desempenho dos animais até a idade de 90 dias. Corroborando, Oliveira et al. (2009b) ao fornecerem a bezerros Girolando lactentes, desmamados precocemente aos 60 dias de vida, dietas com concentrado, concentrado mais feno de leucena (Leucaena leucocephala) e concentrado mais feno de alfafa, não observaram diferenças significativas entre os consumos de matéria seca total.

Verifica-se que partir da oitava semana (57 dias) os bezerros apresentaram maior consumo de matéria seca total e a melhor eficiência de utilização dos alimentos, estando essas variáveis relacionadas com o desenvolvimento do rúmen. Segundo Oliveira et al. (2007), com oito semanas de idade os compartimentos estomacais de bezerros alimentados precocemente, alcançam a proporção de animais adultos, com o retículo-rúmen representando $80 \%$ do estômago e os níveis de acetato, proprionato e butirato são considerados adequados para sustentar energeticamente o animal. Neste ensaio, as diferenças significativas entre os tratamentos foram observadas nos intervalos de 71-84 dias, onde os animais alimentados com feno fornecido a partir do $30^{\circ}$ dia de vida (T3) apresentaram consumo de matéria seca total superior aos do grupo controle (T1) e dos que receberam feno a partir do $15^{\circ}$ dia de vida (T2); e no intervalo de 85-90 dias, onde o grupo controle apresentou consumo inferior aos demais tratamentos (tabela VII).

Os consumos de proteína bruta (CPB) e de fibra em detergente neutro (CFDN) nos animais do grupo controle (T1) foram inferiores aos animais que receberam ração mais feno (tabela V). Todavia, o maior aporte de nutrientes ingeridos nos animais alimentados com feno não foi suficiente para promover incrementos significativos no ganho de peso diário (tabela VI) e no crescimento corpóreo (tabela VIII). Oliveira et al. (2009b), ao trabalharem em condições semelhantes não observaram diferenças significativas de bezerros lactentes recebendo ração con- 


\section{OLIVEIRAETAL.}

Tabela $\boldsymbol{V}$. Consumos de proteína bruta (CPB) e fibra em detergente neutro (CFDN), na ração, feno e dieta total. (Crude protein intake and neutral detergent fiber from the ration, hay and total diet).

\begin{tabular}{lccccc}
\hline & \multicolumn{4}{c}{ Tratamentos } & CV (\%) \\
& T1 & T2 & T3 & T4 & \\
\hline CPB & & & & & \\
Ração (g/dia) & $160,39^{\mathrm{a}}$ & $189,53^{\mathrm{a}}$ & $211,77^{\mathrm{a}}$ & $171,85^{\mathrm{a}}$ & 55,60 \\
Feno (g/dia) & $0,00^{\mathrm{b}}$ & $34,17^{\mathrm{a}}$ & $51,30^{\mathrm{a}}$ & $57,40^{\mathrm{a}}$ & 42,61 \\
$\quad$ Total (g/dia) & $160,39^{\mathrm{b}}$ & $218,82^{\mathrm{a}}$ & $248,41^{\mathrm{a}}$ & $198,22^{\mathrm{a}}$ & 34,94 \\
CFDN & & & & & \\
Ração (g/dia) & $130,20^{\mathrm{a}}$ & $149,15^{\mathrm{a}}$ & $168,94^{\mathrm{a}}$ & $139,23^{\mathrm{a}}$ & 29,47 \\
Feno (g/dia) & $0,00^{\mathrm{b}}$ & $118,07^{\mathrm{a}}$ & $173,10^{\mathrm{a}}$ & $191,05^{\mathrm{a}}$ & 43,58 \\
Total (g/dia) & $130,20^{\mathrm{b}}$ & $250,35^{\mathrm{a}}$ & $292,58^{\mathrm{a}}$ & $226,98^{\mathrm{a}}$ & 24,33 \\
\hline
\end{tabular}

a,bMédias seguidas de letras diferentes, na mesma linha, diferem significativamente entre si pelo Teste de Tukey $(p<0,05)$.

$\mathrm{T} 1=$ ração; $\mathrm{T} 2=$ ração mais feno aos 15 dias; $\mathrm{T} 3$ = ração mais feno aos 30 dias; $\mathrm{T} 4=$ ração mais feno aos 60 dias. $\mathrm{CV}=$ coeficiente de variação.

centrada, em relação aos animais que receberam ração mais feno de alfafa ou feno de leucena. Neste caso, os bezerros foram desmamados aos 60 dias após o nascimento e apresentaram consumos médios de 116,7; 100,0 e 0,79 g para as variáveis CPBT, CFDNT e CA, respectivamente.

Quanto ao ganho de peso dos animais, pode-se observar neste ensaio que as dietas testadas apresentaram comportamento estatisticamente semelhante $(\mathrm{p}>0,05)$ no período total (tabela VI). Resultados semelhantes foram observados por Lizieire et al.
(2002) e Oliveira et al. (2009b), os quais também não observaram diferenças significativas nas variáveis de peso corpóreo final e ganho de peso médio diário nos bezerros lactentes alimentados com leite mais ração em relação aos que receberam leite mais ração mais feno.

Infere-se ainda, que o ganho de peso dos bezerros potencializou-se com a ingestão de alimentos sólidos, tornando-se mais expressivo no final do período experimental devido a maior capacidade ruminal (tabela VII). Todavia, no último intervalo de

Tabela VI. Pesos corpóreos inicial e final e ganho de peso médio diário (GMD). (Initial and final body weights and average daily weight gain).

\begin{tabular}{lccccc}
\hline & \multicolumn{2}{c}{ Tratamentos } & CV (\%) \\
& T1 & T2 & T3 & T4 & \\
\hline Peso corpóreo (kg) & & & & & \\
$\quad$ Inicial & 34,60 & 35,60 & 43,95 & 33,75 & 16,38 \\
Final & 87,30 & 98,80 & 100,00 & 88,95 & 12,81 \\
GMD (kg) & 0,596 & 0,702 & 0,623 & 0,613 & 21,95 \\
\hline
\end{tabular}

Não foram detectadas diferenças significativas pelo teste de $F(p>0,05)$.

$\mathrm{T} 1=$ ração; $\mathrm{T} 2=$ ração mais feno aos 15 dias; $\mathrm{T} 3=$ ração mais feno aos 30 dias; $\mathrm{T} 4=$ ração mais feno aos 60 dias. $\mathrm{CV}=$ coeficiente de variação.

Archivos de zootecnia vol. 62, núm. 239, p. 362. 


\section{DESALEITAMENTO DE BEZERROS LEITEIROS COM USO DE VOLUMOSO}

avaliação ( 85 ao $90^{\circ}$ dia) foi constatada uma acentuada diminuição no ganho de peso nos animais que receberam somente ração concentrada (tratamento controle - T1), sendo esse efeito atribuído a um principio de paraqueratose, já que os animais apresentaram redução no consumo e uma pequena distensão ruminal. Segundo Brandini (1996), a paraqueratose pode difi- cultar a absorção dos ácidos graxos voláteis produzidos no rúmen pela fermentação da dieta, ocasionando um quadro metabólico de timpanismo; caracterizado pela incapacidade do animal em expulsar os gases produzidos através dos mecanismos fisiológicos normais, com consequente redução no consumo e no ganho de peso.

McGavin e Morill (1976), ao trabalharem

Tabela VII. Consumo de matéria seca e ganho de peso médio diário. (Intake of dry matter and average daily weight gain).

\begin{tabular}{|c|c|c|c|c|c|c|c|}
\hline & \multicolumn{7}{|c|}{ Intervalos de avaliação (dias) } \\
\hline & $0-14$ & $15-28$ & $29-42$ & $43-56$ & $57-70$ & $71-84$ & $85-90$ \\
\hline \multicolumn{8}{|c|}{ Consumo de MS (kg/d) } \\
\hline \multicolumn{8}{|c|}{ Ração } \\
\hline $\mathrm{T} 1$ & $0,089^{a}$ & $0,211^{\mathrm{a}}$ & $0,402^{\mathrm{a}}$ & $0,721^{\mathrm{a}}$ & $1,084^{\mathrm{a}}$ & $1,235^{\mathrm{a}}$ & $1,367^{\mathrm{a}}$ \\
\hline T2 & $0,048^{a}$ & $0,158^{\mathrm{a}}$ & $0,289^{a}$ & $0,631^{a}$ & $1,053^{\mathrm{a}}$ & $1,449^{a}$ & $2,249^{a}$ \\
\hline T3 & $0,150^{\mathrm{a}}$ & $0,247^{\mathrm{a}}$ & $0,451^{\mathrm{a}}$ & $0,723^{a}$ & $0,859^{a}$ & $1,697^{\mathrm{a}}$ & $2,186^{a}$ \\
\hline T4 & $0,100^{\mathrm{a}}$ & $0,136^{a}$ & $0,271^{\mathrm{a}}$ & $0,592^{\mathrm{a}}$ & $0,934^{a}$ & $1,356^{\mathrm{a}}$ & $1,743^{\mathrm{a}}$ \\
\hline CV $(\%)$ & 51,14 & 42,45 & 43,67 & 41,04 & 34,35 & 30,65 & 37,48 \\
\hline \multicolumn{8}{|c|}{ Consumo de feno $(\mathrm{kg} / \mathrm{d})$} \\
\hline $\mathrm{T} 1$ & - & - & - & - & - & - & - \\
\hline T2 & - & 0,040 & $0,095^{a}$ & $0,147^{a}$ & $0,313^{a}$ & $0,378^{a}$ & $0,542^{a}$ \\
\hline T3 & - & - & $0,169^{a}$ & $0,260^{\mathrm{a}}$ & $0,364^{a}$ & $0,503^{a}$ & $0,579^{a}$ \\
\hline T4 & - & - & - & - & $0,279^{a}$ & $0,421^{\mathrm{a}}$ & $0,387^{a}$ \\
\hline CV $(\%)$ & & & 43,22 & 47,14 & 31,7 & 46,45 & 31,85 \\
\hline \multicolumn{8}{|c|}{ Consumo total $(\mathrm{kg} / \mathrm{d})$} \\
\hline T1 & $0,089^{a}$ & $0,211^{\mathrm{a}}$ & $0,402^{\mathrm{a}}$ & $0,721^{a}$ & $1,084^{a}$ & $1,235^{\mathrm{b}}$ & $1,367^{b}$ \\
\hline T2 & $0,048^{a}$ & $0,198^{\mathrm{a}}$ & $0,384^{a}$ & $0,778^{a}$ & $1,366^{a}$ & $1,621^{b}$ & $2,791^{a}$ \\
\hline T3 & $0,150^{\mathrm{a}}$ & $0,247^{a}$ & $0,607^{a}$ & $0,983^{a}$ & $1,470^{a}$ & $2,200^{\mathrm{a}}$ & $2,765^{a}$ \\
\hline T4 & $0,100^{\mathrm{a}}$ & $0,136^{\mathrm{a}}$ & $0,271^{\mathrm{a}}$ & $0,592^{a}$ & $1,153^{a}$ & $1,776^{a b}$ & $2,286^{a}$ \\
\hline CV(\%) & 50,65 & 43,07 & 40,24 & 37,37 & 29,4 & 21,6 & 26,6 \\
\hline \multicolumn{8}{|c|}{ Ganho de peso médio diário $(\mathrm{kg} / \mathrm{d})$} \\
\hline $\mathrm{T} 1$ & $0,414^{a}$ & $0,398^{\mathrm{a}}$ & $0,452^{\mathrm{a}}$ & $0,696^{a}$ & $0,786^{a}$ & $0,854^{a}$ & $0,533^{b}$ \\
\hline T2 & $0,446^{\mathrm{a}}$ & $0,446^{a}$ & $0,536^{a}$ & $0,789^{a}$ & $0,896^{a}$ & $0,907^{a}$ & $1,158^{a}$ \\
\hline T3 & $0,293^{a}$ & $0,296^{\mathrm{a}}$ & $0,471^{\mathrm{a}}$ & $0,636^{a}$ & $0,875^{a}$ & $1,025^{\mathrm{a}}$ & $0,950^{a}$ \\
\hline T4 & $0,450^{\mathrm{a}}$ & $0,211^{\mathrm{a}}$ & $0,409^{a}$ & $0,634^{a}$ & $0,757^{a}$ & $0,968^{\mathrm{a}}$ & $1,200^{a}$ \\
\hline CV(\%) & 37,25 & 52,17 & 63,97 & 38,08 & 26,0 & 19,5 & 35,84 \\
\hline
\end{tabular}

$\mathrm{T} 1=$ ração; $\mathrm{T} 2=$ ração mais feno aos 15 dias; $\mathrm{T} 3=$ ração mais feno aos 30 dias; $\mathrm{T} 4=$ ração mais feno aos 60 dias.

a,bMédias seguidas de letras diferentes, na mesma coluna, nas respectivas variáveis, diferem significativamente entre si pelo Teste de Tukey $(p<0,05)$. 


\section{OLIVEIRA ETAL.}

com bezerros lactentes que receberam concentrado pobre em fibra observaram papilas ruminais pequenas, nodulares, em forma de couve-flor, com coloração escura e intensa queratinização, com prejuízos na capacidade absortiva dos ácidos graxos voláteis. Todavia, Quigley (2001), ressalta que apesar da paraqueratose ser uma condição metabólica prejudicial, e de muitos bezerros lactentes alimentados com leite e ração concentrada desenvolver esse quadro, o mesmo normalmente é considerado assintomático e geralmente não afeta o desempenho dos animais.

Neste trabalho verificou-se elevados valores nos coeficientes de variação (CV) para os parâmetros avaliados, sendo isso justificável pelo número de repetições utilizado e pela categoria em análise. Nesta fase os bezerros possuem grande variação no consumo de alimentos e, consequentemente, no ganho de peso diário. De acordo com Martuscello et al. (2004), o consumo de matéria seca de 0-7 semanas, de bezerros em aleitamento, promove $\mathrm{CV}$ de até $61,7 \%$. Cunha et al. (2003) também observaram elevada amplitude no $\mathrm{CV}$, quando foi oferecido ração concentrada para bezerros de 0 a 7 semanas de vida; em média o CV do consumo diário foi de 46,2\%, já as observações feitas para a ração concentrada ofertada de 0 a 4 semanas indicaram um $\mathrm{CV}$ de $72,0 \%$. Oliveira et al. (2009b) de maneira similar verificaram elevados CV para consumo de matéria seca e para o ganho de peso diário de 42,61 e de $28,82 \%$, respectivamente. Corroborando, Schalch et al. (2001) ao trabalharem com bezerros em aleitamento também verificaram elevada oscilação no consumo de matéria seca e no ganho de peso diário, com reflexos diretos no $\mathrm{CV}$, com médias de 34,12 e de $28,66 \%$, respectivamente.

Na tabela VIII podem ser observadas as mensurações do perímetro torácico e das alturas de cernelha e garupa. A determinação destes parâmetros é importante, pois permite acompanhar desenvolvimento esquelético do animal, sendo essencial que a bezerra tenha um crescimento corpóreo adequado, já que o tamanho está diretamente relacionado com problemas de distocia e com a futura produção de leite. Neste ensaio, não houve influência das dietas nas variáveis crescimentos de garupa, cernelha e perímetro torácico; ou seja, o desenvolvimento corpóreo dos animais não foi afetado pela presença de feno na dieta.

Abreu (2006), também não observou efeito no crescimento corpóreo com a

Tabela VIII. Medidas das alturas de cernelha e garupa; e do perímetro torácico dos bezerros. (Measurements of withers and rump heights; and the chest girth from the calves).

\begin{tabular}{lccccccccc}
\hline & & \multicolumn{8}{c}{ Medida (cm) } \\
& ACl & ACF & CTC & AGI & AGF & CTG & PTI & PTF & CTPT \\
\hline T1: Ração & 77 & 93 & 16 & 80 & 96 & 17 & 80 & 108 & 28 \\
T2: Ração mais feno aos 15 dias & 75 & 95 & 21 & 77 & 98 & 21 & 81 & 114 & 33 \\
T3: Ração mais feno aos 30 dias & 80 & 95 & 16 & 83 & 97 & 15 & 85 & 112 & 27 \\
T4: Ração mais feno aos 60 dias & 74 & 92 & 18 & 77 & 94 & 18 & 80 & 108 & 28 \\
CV(\%) & 5,14 & 3,48 & 18,97 & 5,03 & 3,59 & 19,79 & 6,01 & 4,73 & 21,67
\end{tabular}

Não foram detectadas diferenças significativas pelo Teste $F(p>0,05)$.

$\mathrm{ACl}=$ Altura da cernelha inicial; $\mathrm{ACF}=$ Altura da cernelha final; $\mathrm{CTC}=$ crescimento total da cernelha; $\mathrm{AGI}=$ altura da garupa inicial; $A G F=$ altura da garupa final; $C T G=$ crescimento total da garupa; $P T I=$ perímetro torácico inicial; PTF= perímetro torácico final; CTPT= crescimento total do perímetro torácico. 


\section{DESALEITAMENTO DE BEZERROS LEITEIROS COM USO DE VOLUMOSO}

Tabela IX. Receita, custo e a relação receita/custo para cada tratamento, em reais. (Revenue, cost and revenue/cost relationship for each treatment, in real).

\begin{tabular}{lcccc}
\hline \multicolumn{4}{c}{ Tratamentos } \\
Indices & T1 & T2 & T3 & T4 \\
\hline Receita & & & & \\
$\quad$ Ganho de peso adquirido*Valor de venda & 343,98 & 412,58 & 365,54 & 360,64 \\
Custo & & & & \\
$\quad$ Leite & 222,72 & 222,72 & 222,72 & 222,72 \\
$\quad$ Ração concentrada & 58,82 & 65,27 & 74,40 & 57,97 \\
$\quad$ Feno de alfafa & 0,00 & 40,52 & 46,03 & 26,55 \\
$\quad$ Total & 281,54 & 328,51 & 343,15 & 307,24 \\
Margem & 62,44 & 84,07 & 22,39 & 53,40 \\
& & & & 1,17 \\
Relação receita/custo & 1,22 & 1,26 & 1,07 & 1, \\
\hline
\end{tabular}

US $\$ 1.00=R \$ 2,0315 ; 1$ arroba $=15 \mathrm{~kg}$.

$\mathrm{T} 1=$ ração; $\mathrm{T} 2=$ ração mais feno aos 15 dias; $\mathrm{T} 3=$ ração mais feno aos 30 dias; $T 4=$ ração mais feno aos 60 dias.

inclusão de feno de alfafa ou leucena na dieta de bezerros lactentes desmamados aos 60 dias, em relação aos que receberam somente ração concentrada; sendo verificadas médias de 13,$3 ; 13,7$ e $20,7 \mathrm{~cm}$ para crescimento total da cernelha (CTC), crescimento total da garupa (CTG) e crescimento total do perímetro torácico (CTPT), respectivamente. Schalch et al. (2001), ao substituírem o grão de milho pela polpa cítrica no concentrado de bezerros Holandeses desmamados precocemente aos 70 dias de vida observaram incrementos na altura de cernelha e do perímetro torácico de 11,7 e $17,5 \mathrm{~cm}$, respectivamente. Modesto et al. (2002) ao avaliarem o desempenho de bezerros alimentados com leite integral ou colostro fermentado, com ou sem óleo e zeranol (promotor de crescimento) observaram aos 60 dias de vida altura de cernelha de $84,0 \mathrm{~cm}$ e perímetro torácico de $89,5 \mathrm{~cm}$. Já Signoretti et al. (1995) e Rocha (1997) relataram, em bezerros leiteiros submetidos a sistemas de desaleitamento precoce com ingestão de rações concentradas, alturas finais de cernelha de 80,0 e $78,2 \mathrm{~cm}$, respectivamente.
Na tabela IX, pode ser visualizada a viabilidade econômica dos tratamentos testados, através da relação receita/custo (R/ $\mathrm{C})$, sendo a receita média por bezerro em cada tratamento, obtido pela multiplicação da cotação do valor de venda dos animais ( $\mathrm{R} \$ 6,53 / \mathrm{kg}$ ) pelo ganho de peso médio adquirido no período, ou seja, 52,7; 63,2; 56,0; $55,2 \mathrm{~kg}$ para os tratamentos T1, T2, T3 e T4, respectivamente; e o Custo médio por bezerro em cada tratamento, composto pelo leite - R \$ 0,64 por litro e pela dieta sólida, ração concentrada e feno de alfafa.

Verifica-se, portanto, que todas as dietas apresentaram relação $\mathrm{R} / \mathrm{C}$ maior que 1 , sendo que o melhor resultado econômico foi obtido no tratamento em que foi fornecido ração mais feno de alfafa a partir dos 15 dias de vida (T2). Assim, neste tratamento, para cada $\mathrm{R} \$ 1,00$ gasto com alimentação, tevese um retorno de 26 centavos, ou seja, de R $\$$ 1,26 .

\section{CONCLUSÃO}

A dieta contendo somente ração concentrada, fornecida a bezerros Girolando 


\section{OLIVEIRA ETAL.}

desmamados aos 90 dias de vida, proporcionou um desempenho semelhante às dietas contendo ração concentrada mais feno de alfafa.

A ingestão do feno ocasionou aumento na conversão alimentar, refletindo numa

\section{BIBLIOGRAFIA}

Abreu, C.L. 2006. Desempenho de bezerros leiteiros lactentes, alimentados com ração concentrada e feno de leucena (Leucaena leucocephala) ou de alfafa (Medicago sativa). Monografia (Graduação em Zootecnia). Universidade Estadual de Mato Grosso do Sul. Aquidauana/MS. 39 pp.

Baldwin, R.L.; McLeod, K.R.; Klotz, J.L. and Heitmann, R.N. 2004. Rumen development, intestinal growth and hepatic metabolism in the pre- and postweaning ruminant. J Dairy Sci, 87 (supplement): E55-E65.

Bermudes, R.F.e Peixoto, R.R. 1997. Avaliação do farelo de arroz na alimentação de bezerros da raça Holandês. Rev Bras Zootecn, 26: 391-395.

Brandini, J.C. 1996. Doenças em bovinos confinados. Embrapa-CNPGC. Documento №65. 62 pp.

Costa, S.F.; Pereira, M.N.; Melo, L.Q.; Resende Júnior, J.C. e Chaves, M.L. 2008. Alterações morfológicas induzidas por butirato, propionato e lactato sobre a mucosa ruminal e a epiderme de bezerros: I- Aspectos histológicos. Arq Bras Med Vet Zoo, 60: 1-9.

Cunha, D.N.F.V.; Lizieire, R.S.; Martuscello, J.A. e Campos, O.F. 2003. Influência da idade ao desaleitamento sobre o desenvolvimento de bezerros mestiços Holandês-Zebu suplementados e não suplementados com cobalto. Rev Univ Rural, Sér Ci Vida, 23: 23-27.

Khan, M.A.; Weary, D.M. and Von Keyserlingk, M.A.G. 2011. Invited review: effects of milk ration on solid feed intake, weaning and performance in dairy heifers. $J$ Dairy Sci, 94: 10711081.

Lizeire, R.S.; Cunha, D.N.F.V.; Martucello, J.A. e Campos, O.F. 2002. Fornecimento de volumoso para bezerros pré-ruminantes. Rev Ciên Rural, 32: 835-840.

Lydorf Jr., S.J. 1988. Growth and development of the ruminant digestive system. In: Church, D.C. The ruminant animal: Digestive, physiology and menor eficiência na utilização dos nutrientes da dieta.

A análise econômica evidenciou que a dieta contendo leite, ração e feno de alfafa a partir dos 15 dias de vida proporcionou a melhor relação receita/custo.

nutrition. Waveland Press. Englewood Cliffs. pp. 44-63.

Martuscello, J.A.; Lizieire, R.S.; Cunha, D.N.F.V.e Campos, O.F. 2004. Efeito da substituição parcial de concentrado inicial por feno de coastcross sobre a performance de bezerros desaleitados precocemente. Rev Univ Rural, Sér Ci Vida, 24: 32-37.

McGavin, M.D. and Morrill, J.L. 1976. Scanning electron microscopy and ruminal papillae in calves fed various amounts and forms of roughage. Am J Vet Res, 37: 497-508.

Modesto, E.C.; Mancio, A.B.; Menin, E.; Cecon, P.R. e Detmann, E. 2002. Desempenho produtivo de bezerros desmamados precocemente alimentados com diferentes dietas líquidas com utilização de promotor de crescimento. Rev Bras Zootecn, 31: 429-435.

Nielsen, P.P. 2008. Behaviours related to milk intake in dairy calves - The effects of milk feeding and weaning methods. Doctoral Thesis. Swedish University of Agricultural Sciences, Skara. 53 pp.

NRC. 2001. National Research Council. Nutrient requirements of dairy cattle. $7^{\text {th }}$ ed. rev. Washington. $381 \mathrm{pp}$.

Nussio, C.M.B.; Santos, F.A.P.; Zopollatto, M.; Pires, A.V.; Morais, J.B. e Fernandes, J.J.R. 2003. Parâmetros de fermentação e medidas morfométricas dos compartimentos ruminais de bezerros leiteiros suplementados com milho processado (floculado vs. laminado a vapor) e monensina. Rev Bras Zootecn, 32: 1021-1031.

Oliveira, J.S; Zanine, A.M. e Santos, E.M. 2007. Fisiologia, manejo e alimentação de bezerros de corte. Arq Ciên Vet Zool, 10: 39-48.

Oliveira, M.V.M.; Figueiró, R.N.; Barbosa, C.S.; Luz, D.F. e Simões, A.R.P. 2009a. Criação de bezerras leiteiras durante a fase de aleitamento. Série Bovinocultura Leiteira. Editora UEMS. Dourados. MS. 80 pp. 


\section{DESALEITAMENTO DE BEZERROS LEITEIROS COM USO DE VOLUMOSO}

Oliveira, T.S.; Abreu, C.L.; Bonatti, F.K.Q.; Silva, C.J.; Oliveira, M.V.M. e Pereira, J.C. 2009b. Desempenho de bezerros leiteiros lactentes alimentados com ração concentrada e feno de leucena ou feno de alfafa. In: $46^{\circ}$ Reunião Anual da Sociedade Brasileira de Zootecnia. Anais... Maringá-PR.

Quigley, J. 2001. What is rumen abrasive value? Calf Notes, $\mathrm{n}^{\circ}$ 63. <http://www.calfnotes.com/ pdffiles/CN063.pdf> (16/04/2011).

Rocha, E.O. 1997. Sistemas de aleitamento artificial, exigências nutricionais e características produtivas de bovinos de origem leiteira. Tese (Doutorado em Zootecnia). Universidade Federal de Viçosa. Viçosa/MG. 143 pp.

SAS. 2002. Statistic analisys system. User's guide. S.A.S. Institute Inc. Cary. NC. USA. 137 pp.

Schalch, F.J.; Schalch, E.; Zanetti, M.A. e Brisola, M.L. 2001. Substituição do milho em grão moído pela polpa cítrica na desmama precoce de bezerros leiteiros. Rev Bras Zootecn, 30: 280285.

Signoretti, R.D.; Castro, A.C.G.; Silva, J.F.C.; Cam- pos, J.M.S.; Cecon, P.R. e Valadares Filho, S.C. 1995. Utilização do farelo de gérmen de milho no concentrado inicial de bezerros de raças leiteiras em sistemas de desaleitamento precoce. Rev Bras Zootecn, 24: 847-851.

Silva, D.J. e Queiroz, A.C. 2002. Análises de alimentos: Métodos químicos e biológicos. $2^{\mathrm{a}}$ ed. Editora UFV. Viçosa. MG. 165 pp.

Suárez, B.J.; Van Reenen, C.G.; Stockhofe, N.; Dijkstra, J. and Gerrits, W.J.J. 2007. Effect of roughage source and roughage to concentrate ratio on animal performance and rumen development in veal calves. J Dairy Sci, 90: 2390-2403.

Valadares Filho, S. C. 2000. Nutrição, avaliação de alimentos e tabelas de composição de alimentos para bovinos. In: $37^{\circ}$ Reunião Anual da Sociedade Brasileira Zootecnia. Anais... pp. 267-337.

Zitnan, R.; Kuhla, S.; Sanftleben, P.; Bilska, A.; Schneider, F.; Zupcanova, M. and Voigt, J. 2005. Diet induced ruminal papillae development in neonatal calves not related with rumen butyrate. Vet Med Czech, 50: 472-479. 